\section{DISEASE OF THE PANCREAS.}

\section{To the Editor of The LanceT.}

SIR, - I shall be obliged by your giving the accompanying case a place in your Journal, and remain, Sir, your obedient servant,

\section{W. B. Whitfield.}

64, Lamb's Conduit-street, June 13, 1842.

Mary Cattwood, a laundress, fifty-seven years of age, living in'Theobald's-road, applied to me on October 18, 1841. She gave the following account of herself :-About six weeks previous she had first experienced a pain of an acute character in the upper part of the abdomen, after severe exertion, on carrying water up-stairs; the pain lasted for several hours, but was mitigated by taking some aperient medicine ; it never, however, entirely ceased, but became more dull and aching, accompanied with a sense of weight. A fortnight after this she felt herself becoming very weak, and she observed that her abdomen had increased in size, while her flesh had fallen away considerably. She then applied to St. Bartholomew's Hospital for relief, and became an out-patient at that excellent institution; the abdomen, however, increased in size, and her strength became so much reduced as to confine her to bed, when she applied for a parochial order, and became my patient.

At this time her emaciation was considerable; the countenance sallow, and expressive of anxiety; the pulse quick and feeble; the skin hot and dry; the abdomen, very much distended with fluid, felt tense and hard, with evident fluctuation; no indication of enlargement of any of the abdominal viscera could be detected. The chest, upon examination, appeared free from disease, and the urine, small in quantity, contained no morbid ingredients.

She complained of a dull pain, with occasional sharper twinges in the umbilical and lower part of the epigastric regions, but there was very slight tenderness. Leeches were applied to the seat of pain, and jalap with bitartrate of potass given as hydragngues. The leeches relieved the pain for a time, but it returned with increased violence: it afterwards became less constant, and she had occasional long intervals of comparative ease. The hydragogues, after a fortuight's continuance, almost entirely removed the effused fluid. She now began to suffer from vomiting, which became so obstinate that little food could be retained in the stomach. Upon examination of the abdomen a hard cord-like swelling could be felt stretching atcross the umbilical region: it could be readily lifted like a flap from below, but was not moveable in a downward direction. Its largest extremity was imper- fectly distinguished in the right hypochondriac region. Hydrocyanic acid and small doses of laudanum in milk checked the vomiting for a time, but she continued to " bring up" the greatest portion of her food until the day of her death.

Blister's were repeatedly applied to the epigastrium, and the iodine ointment was freely rubbed over the umbilical region, but without much benefit. The emaciation increased, the vomiting became less under control, she suffered very much from flatulence, and she died of exhaustion and inanition on the 6th of November.

\section{Examination Thirty-six Hours after Death.}

The organs contained in the head and chest presented no marks of disease.

The stomach, very much distended, contained two quarts of a dirty-brown fluid, in other respects it was healthy.

The pancreas, very much enlarged, felt hard; its head, from increase of size, pressed so much upon the duodenum and pylorus, as must have occasioned great difficulty in the passage of aliment from the stomach.

Upon cutting through the cellular coat of the organ, it was found that its hardness depended entirely upon its cellular coat, as its internal structure was reduced throughout into a semi-purulent mass, resembling cream, in which no trace of the original structure could be traced. No other morbid appearances of moment presented themselves.

Remarks. - It is not often that we find disease of the pancreas so extensive and severe as to occasion death; but there can be no question that the symptoms observed during life were entirely owing to the pancreatic affection. The vomiting and pain were obviously owing to this cause, and no doubt the ascites had the same origin as the enlargement of the pancreas, for pressing upon the mesenteric veins, is sufficient cause for the passive effusion. The change of structure I attribute to chronic inflammation, terminating in softening and purulent infiltration. I may observe, that I have not hitherto been able to find on record a case which has presented the same features.

\section{CASE OF POLYPUS OF THE UTERUS.}

By John Lindley, Esq., Surgeon, Derby.

Mrs. Dunstone, aged 47 , resides at Quorndon, four miles from this place, has had nine children; the last is three years and a half old, appears much reduced, and beara evident marks of great loss of blood; states that her medical attendants have for some time given her up as incurable; has worn a pessary for a supposed inversion of the aterus, which was discontinued, owing to the pain it produced. She describes the first appearance of the disease as taking place 
eighteen months back, under great mental anxiety. On going up-stairs she fancied something gave way, and fell from the womb into the parts below : this was followed by a profuse hremorrhage, when medical assistance was sent for, attended with some relief. The bleeding, however, returned at intervals for a few months, when it gradually gave way, and was succeeded by an offensive watery discharge (occasionally grumous), shooting pains in the region of the womb, cramps of the lower extremities, with a total incapability of voiding her urine without the assistance of the catheter, as well also of the freces without injections; the catamenia regular.

On making an examination per vaginam, a round, hard, and somewhat uneven substance presented itself, filling the basin of the pelvis. With considerable difficulty part of my hand was introduced into the vagina, by which means $I$ could distinctly feel the body of the tumour, becoming less towards the uterus. From its great size, however, and it having forced this body high into the abdomen, the cervix uteri could not be distinguished. The tumour was quite insensible to the touch, and incapable of the least reduction without causing pain. After withdrawing my hand a probe was found to pass between the vagina and the tumour to at least eight inches, without resistance. From this examination, also, the colour of the tumour, which might be seen at the entrance of the vulva, of a light grey, $I$ concluded that it must be a polypus of the uterus, and not an inversion of that organ.

On the 23rd of May, accompanied by my friends Dr. Heygate and Mr. Webster, surgeon, who coincided with the above opinion, I proceeded to pass a ligature round the neck of the polypus in the usual manner, by the assistance of a double silver canula. In a few minutes the ligature was fairly applied: it was then gently tightened upon the instrument, and by measuring the cord before and after the operation, we found it gave a circumference of seven inches over the neck of the polypus. On the following day the canulæ were discovered an inch higher in the body, and the ligature, without using much force, or giving pain to the patient, capable of being drawn out three inches, leaving four encircling the neck of the polypus.

It will be unnecessary to detail all the symptoms which ensued; I may, however, remark, that early on the third day much constitutional disturbance arose, attended with sickness and vomiting, a distressing bearing down of the uterus, great tenderness and tumefaction of the abdomen, with a pulse of 110. These symptoms were soon mitigated by a small bleeding and large doses of opium. From this time the substance lost all vitality; it became softer, and, as the discharge increased, rapidly smaller. The liga- ture was gently made tense round the end of the instrument for seven days, when at the end of this period straining supervened, and was shortly relieved by the escape of the polypus.

In circumference it measured thirteen inches, and in length nine; its weight was a pound and a half; its internal structure fleshy, very much resembling a large afterbirth.

June 8 . She is now well, and able to go about her employment.

This case $I$ consider interesting in many points : it first shows how liable practitioners are to mistake a polypus of this part for the uterus itself. The large size of the neck, also, is a point of interest; though, when we take into consideration the maguitude of the polypus (which could not be less than fifteen inches in girth, when in the body), and the consequent difficulty of placing a ligature exactly over its pedicle, it is highly probable the thinnest portion was not encircled by the ligature in the first instance: this I believe to have been the case, as it was not until the third day, when my ligature inad been drawn out, so as to have only four inches round the neck of the polypus, that any constitutional irritation was set up.

I am of opinion the most judicious plan of tightening ligatmes over polypi of this nature is to co it very gradually at first, and not to be too anxious to get them within the uterus; having found in two other cases lately under my care, that when the ligature was not exactly round the neck, it shortly finds its way there, from the shape of the polypus having a tendency to force it upwards, which is also increased by a temporary enlargement of its substance. This plan, moreover, is least likely to injure the fundus of the uterus in cases of partial inversion.

The case also shows the large size polypi occasionally acquire in this part of the body, without producing speedy dissolution; also the propriety of operating where the os uteri cannot be felt.

The fleshy placenta-like nature of the polypus favours the theory first promulgated by the late $\mathrm{Mr}$. Abernethy, that such tumours form from, or rather origivate in, a clot of blood becoming organised, which, as Mr. A. observes, receive their ressels from the sur. rounding parts, but afterwards live and grow by their own inherent power's.

In conclusion, I cannot help thinking how singularly deficient our nomenclature is with regard to tumours of the uterus; pendulous bodies growing from this organ, whether of the semi-cartilaginous, fibrous, membranous, or, as in this case, sarcomatous structure, have all received the name of polypi; thus confounding diseases of a widely opposite nature. May not the form of some tumours be entirely owing to the constricting powers of the os uteri?

Derby, June 9, 1842. 